\title{
Os desafios à educação cooperativista: análise de uma experiência em uma cooperativa de crédito na Bahia
}

\author{
Challenges to cooperative education: an analysis of an experience in a credit \\ cooperative in Bahia
}

\begin{abstract}
Resumo
O presente trabalho analisa a experiência da educação cooperativista em uma Cooperativa de Crédito. Buscouse compreender a concepção sobre a educação cooperativista que norteia a cooperativa para analisar o processo de formação dos dirigentes, colaboradores e associados. Ademais, avaliamos se os sócios que tiveram acesso às atividades de formação participam mais efetivamente do cotidiano e dos processos decisórios. Para tanto, optou-se pelo estudo de caso em uma cooperativa de crédito situada no município de Governador Mangabeira, no Território do Recôncavo, na Bahia. Foram 17 entrevistas mais o diário de campo elaborado com as observações realizadas durante os períodos de estágios da pesquisadora. As análises revelaram que a cooperativa terá inúmeros desafios para desenvolver um programa de educação cooperativista que seja permanente e contínuo para seus sócios, colaboradores e dirigentes, pois somente assim poderá assegurar a participação democrática nos processos decisórios.
\end{abstract}

Palavras-chave: Educação Cooperativista, Participação, Cooperativa de Crédito.

\begin{abstract}
This paper analyzes the experience of cooperative education in a Credit Cooperative. We sought to understand the conception of cooperative education that guides the cooperative to analyze the process of training of managers, employees and associates. In addition, we evaluate if the members who had access to the training activities participate more effectively in the daily life and in the decision-making processes. Therefore, we chose a case study in a credit cooperative located in the municipality of Governador Mangabeira, in the Territory of Recôncavo, Bahia. There were 17 interviews plus the field diary drawn up with the observations made during the trainees' periods of the researcher. The analyzes revealed that the cooperative will have numerous challenges to develop a program of cooperative education that is permanent and continuous for its partners, employees and leaders, since only this way can ensure democratic participation in decision-making processes.
\end{abstract}

Keywords: Cooperative Education, Participation, Credit Cooperative.

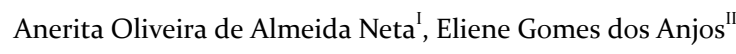

${ }^{\text {I}}$ Universidade Federal do Recôncavo da Bahia. netta.oliveira.5@gmail.com

${ }^{\text {II } U n i v e r s i d a d e ~ F e d e r a l ~ d o ~ R e c o ̂ n c a v o ~ d a ~ B a h i a . ~ e l i e n e a n j o s 7 @ g m a i l . c o m ~}$ 


\section{Introdução}

As cooperativas devem proporcionar educação e treinamento aos seus cooperados, colaboradores e dirigentes a fim de contribuir efetivamente para o seu desenvolvimento. Dentre os sete princípios do cooperativismo a "educação, formação e informação" é considerado um dos princípios mais importantes e indispensáveis, porém algumas instituições cooperativas, principalmente as do ramo crédito, por competir com grandes instituições financeiras, tendem a se distanciar ou não executar atividades que propaguem o cooperativismo e seus princípios.

Nessa perspectiva de análise, a motivação para realizar essa pesquisa foi compreender os desafios para assegurar a educação cooperativista no cooperativismo de crédito. Assim, definimos como objetivo principal analisar uma experiência de educação cooperativista no ramo crédito. Os objetivos específicos buscam compreender a concepção sobre a educação cooperativista que norteia a cooperativa objeto empírico do estudo; entender o processo de formação dos dirigentes, colaboradores e os associados e, por fim, verificar se entre os sócios que tiveram acesso às atividades de formação, se havia uma participação mais efetiva no cotidiano e nos processos decisórios.

A cooperativa estudada localiza-se no município de Governador Mangabeira e possui um ponto de atendimento no município de Cabaceiras do Paraguaçu, ambos no Recôncavo da Bahia. A escolha do empreendimento se deu pela vivência propiciada no período de estágio supervisionado da pesquisadora, em 2017. Nesta convivência, com os colaboradores e parte da direção da cooperativa à época, asseguraram existir atividades de educação cooperativista para os sócios e funcionários. Afirmaram, também, que esta prática era o diferencial da cooperativa de crédito para com as suas congêneres, porém observou-se na prática que a falta de participação dos sócios era flagrante, indicando deficiências na suposta formação educativa.

Para alcançar os objetivos propostos, este estudo utilizou uma abordagem qualitativa, com um caráter descritivo e exploratório. Realizou-se um levantamento bibliográfico e coleta de dados primários com a pesquisa empírica. As técnicas utilizadas para obter os dados foram o diário de campo, elaborado a partir das observações realizadas durante o estágio supervisionado no período de julho a setembro de 2017, e a realização de 17 entrevistas baseadas em dois roteiros semiestruturados. Um roteiro orientou as 10 entrevistas com os sócios e o outro roteiro destinava-se aos o5 colaboradores e 2 membros da diretoria. Todas as entrevistas foram gravadas e transcritas para posterior análise do seu conteúdo. Para a identificação dos entrevistados, optamos por nomes fictícios para preservar suas identidades, tanto para manter a humanidade desses sujeitos e ser mais fiel à realidade estudada.

Quanto à estrutura desse artigo, além dessa introdução, nas duas próximas seções apresentamos um debate teórico acerca da educação cooperativista e suas correlações com a participação e sua forma mais qualificada, a autogestão. Em seguida, uma breve caracterização do cooperativismo de crédito, para, logo depois, apresentar o caso estudado em profundidade. Nas considerações finais sumarizamos os desafios que a cooperativa terá de travar para implementar um programa de educação cooperativista que busque qualificar dirigentes e colaboradores para uma gestão eficientes, mas, sobretudo, terá que desenvolver ações que motive à participação, condição elementar para prática autogestionária.

\section{Educação cooperativista: um princípio a ser assegurado}

A educação cooperativista é imprescindível para as cooperativas porque é a partir desse processo que os associados passam a conhecer melhor o empreendimento a qual pertencem e, acima de tudo, participam de forma qualificada nos processos decisórios. Sua relevância é tanta que o quinto princípio do cooperativismo orienta sua prática: "Educação, formação e informação".

A Organização das Cooperativas Brasileiras (OCB) apregoa que as sociedades cooperativas devem promover a educação e a formação de seus membros, dos representantes eleitos e dos trabalhadores contratados. Destaca, também, que a formação não pode ser restrita ao ambiente interno da organização, pois o público em geral deve ser informado sobre a natureza e as vantagens da cooperação. Para Schneider (2003), o processo educativo que deveria ser assegurado de forma 
continua e permanente nas cooperativas assegura a coerência com seus princípios, uma vez que a acirrada competição enfrentada no sistema capitalista poderia desvirtuá-las.

Um instrumento importante criado para fortalecer a educação cooperativista foi o Fundo de Assistência Técnica, Educacional e Social - FATES, utilizado para fomentar a educação e a capacitação técnica dos associados, como também dos seus familiares, pois o fundo é indivisível entre os sócios.

A lei 5.764/71, capítulo VII, parágrafo II, referente aos fundos, institui que:

Fundo de Assistência Técnica, Educacional e Social, destinado à prestação de assistência aos associados, seus familiares e, quando previsto nos estatutos, aos empregados da cooperativa, constituído de $5 \%$ (cinco por cento), pelo menos, das sobras líquidas apuradas no exercício. (BRASIL, 1971, p.6.).

Por sua vez, Vieira e Ricci (2007) entendem que a educação e a capacitação do sócio são exigências essenciais para que possa entender a natureza do empreendimento cooperativo, uma vez que assume responsabilidades no empreendimento e pelo empreendimento. Cabe a ele gerir o empreendimento por meio dos órgãos competentes, garantindo a idoneidade civil e comercial diante de outros agentes econômicos e a sociedade em geral.

Schneider (2003) afirma que "educar para cooperar é uma tarefa difícil, pois as pessoas nascem, crescem e vivem num contexto de concorrência, de individualismo, do crescimento deixando os outros para trás. " (p.14). Analisando o contexto histórico, no qual a competição e o individualismo prevalecem em nossa realidade, na família, na escola, no trabalho e em outros espaços de socialização, estamos sempre sendo estimulados á competição em detrimento da cooperação.

Para que haja uma mudança nesse contexto, deve-se realizar um trabalho árduo de desconstrução desses pensamentos, porém Schneider (2003) pondera que "não se consegue mudar uma situação de concorrência para uma situação de ajuda mútua de uma hora para outra. Desencadeia-se um processo, cujo resultado geralmente só se obtém a longo prazo.” (p. 14). A educação cooperativista, portanto, é um processo longo e complexo que busca o aprimoramento organizacional da cooperativa e o desenvolvimento humano do associado.

A concepção processual na educação cooperativista impõe-se porque as pessoas não deixarão a lógica da individualidade simplesmente porque se tornaram sócias de um empreendimento cooperativo que tem como primazia alcançar objetivos em comum. Com essa perspectiva de análise, Schneider (2003) identifica alguns problemas que devem ser considerados nos projetos de educação desenvolvidos pelas cooperativas conforme descritos em sequência abaixo:

a) A consciência das etapas na história da administração das cooperativas. Refere-se às características das práticas de gestão de cada cooperativa que se diferenciam de uma para outra, como o tipo, o tamanho, o nível de educação dos cooperados, o estágio de desenvolvimento da cooperativa, o nível de participação dos sócios na Assembleia, no Conselho de Administração e Fiscal, ou em qualquer outra atividade em que o sócio participe como coproprietário.

b) Falta de participação do sócio. Apesar do sócio ser dono do empreendimento, porém não se sente como tal e, por conta disso, não participa.

c) O ambiente pouco participativo das assembleias gerais. Normalmente apresentam um caráter formal e protocolar, numa linguagem pouco acessível à maioria dos associados dificultando assim, a participação dos sócios.

d) Infidelidade do sócio. É comum a infidelidade principalmente nas cooperativas agropecuárias, os sócios preferem entregar seus produtos onde o preço esteja maior, muitas vezes deixam de abastecer a cooperativa para vender a mercados concorrentes, no intuito de ganhar mais, mesmo que seja momentâneo. Outra razão é o sócio não se identificar como beneficiário e responsável pelos serviços da cooperativa.

e) A relação entre poder e saber. Para assegurar o controle democrático na cooperativa, deve imperar um regime de liberdade, de reunião, de opinião, ou de voto, relativo à inserção no mercado e 
no processo de gerência dos negócios, onde as limitações que se colocam sejam apenas as derivadas das necessidades do fim do coletivo.

f) Necessidade de sobreviver em meio a concorrência, ou de servir ao sócio. Considerar que as cooperativas possuem função social e comercial, se optarem a servir apenas ao cooperado nas suas necessidades, estão em desvantagem, ao terem que concorrer com poderosas empresas que seguem exclusivamente a lógica do mercado e do lucro.

g) Pouca flexibilidade nas decisões. A perspectiva democrática não deve diminuir à flexibilidade e a rapidez das cooperativas. Os gerentes podem tomar decisões diárias com rapidez, porém decisões importantes e de longo alcance são da alçada da assembleia geral.

h) Os impasses da capitalização. Na cooperativa o sócio é remunerado na proporção de suas operações com a organização, já nas empresas concorrentes a remuneração é de acordo com a quantidade de capital investido, fazendo com que a cooperativa não seja a melhor opção de retorno para os investidores de capital.

i) Controle estatal. O Estado deve se limitar ao encorajamento e, às vezes, colaborar financeiramente, mas nunca querer dirigir, dominar ou interferir.

j) Intercooperação. Um dos princípios adotados pela Aliança Cooperativa Internacional, porém os resultados obtidos desde então estão longe dos esperados, pois há sérias dificuldades para efetivar a intercooperação na realidade brasileira.

k) A relação entre gerência e conselho administrativo. É preciso que haja distinção nas funções desempenhadas pela gerência e o conselho de administração para um não interferir nas ações do outro.

l) O menosprezo pela educação/capacitação cooperativa. Na teoria se exalta a importância da educação, mas, na prática, pouco se efetiva.

Apesar do reconhecimento da educação cooperativista na teoria, na prática poucas são as cooperativas que efetivamente conseguem implementá-la. Essa constatação é reafirmada também por Ferreira, Sousa e Amoedo (2018) em pesquisas realizadas com cooperativas agropecuárias de Minas Gerais. Os autores constataram que a grande maioria das cooperativas pesquisadas reconhecem a importância da educação cooperativista, porém somente metade realizam atividades com essa finalidade.

Justamente pela necessidade de efetivar uma educação cooperativa que surgiu no Brasil o Sescoop, em 1999, sob gestão da Organização das Cooperativas Brasileiras (OCB). Seu objetivo principal é formar cooperados, dirigentes e empregados, contribuindo com a profissionalização da gestão em seus diversos aspectos. Além disso, assessora o governo federal na formulação de políticas públicas para fortalecer o campo do cooperativismo (FERREIRA; SOUSA, 2018).

O surgimento da Sescoop, no entanto, não assegurou formação a todas as cooperativas do Brasil. Sua receita é oriunda da contribuição de $2,5 \%$ da folha de pagamento das cooperativas, todavia, por ser administrada pela OCB, como é ressaltado por Ferreira e Souza (2018), as cooperativas que não estão filiadas a essa organização "não teriam acesso à capacitação, nem mesmo aos fundos e à direção do Sescoop". (p.777) ${ }^{1}$.

Apesar das limitações para assegurar formação adequada aos associados das cooperativas, Ferreira, Sousa e Amoedo (2018) ressaltam o caráter multidimensional dessa modalidade de empresa, ou seja, a dimensão social, por assumir um formato associativo, e a dimensão econômica, pela necessidade de ser gerida com eficiência e demandar uma gestão profissionalizada. Com essa perspectiva, os autores concluem que as cooperativas que não adotam a educação cooperativista dificilmente funcionarão adequadamente, cumprindo com seus objetivos e não responderão as transformações impostas ao ambiente organizacional.

\footnotetext{
1 Na última década do século XX no Brasil surgiram várias cooperativas impulsionadas pelos movimentos sociais e identificadas com a economia solidária. Essas cooperativas criaram suas organizações representativas como a União Nacional das Cooperativas de Agricultura Familiar e de Economia Solidária (Unicafes), a Confederação das Cooperativas de Reforma Agrária do Brasil (Concrab) e a União e Solidariedade das Cooperativas e Empreendimentos de Economia Social do Brasil (Unisol).
} 


\section{Participação e autogestão: duas faces da mesma moeda}

Quando falamos em participação, lembramo-nos de dois princípios do cooperativismo, quais sejam: controle democrático dos sócios e participação econômica dos sócios. O primeiro responsabiliza os associados pela organização das atividades, pelas tomadas de decisão e ressalta o poder de participação ao instituir a relação "um homem um voto". Já o segundo se refere à questão do capital, o qual todos são donos e têm, portanto, direito a participar dos rendimentos e das decisões sobre a sua destinação. Nesse cenário, a participação não é somente um instrumento para socializar resultados econômicos de forma mais equitativa, mas a possibilidade de romper com relações de subordinação e vivenciar, de fato, uma gestão democrática.

Para Bordenave (1985), a participação pode assumir diversas maneiras e expressões, porém, destaca que a forma mais avançada é a denominada de autogestão. A autogestão, nesse sentido, é o mais alto grau de participação, é a forma de gestão mais democrática e justa a ser adotada pelos empreendimentos coletivos. Acompanhada da participação voluntária, essas organizações têm maior chance de sobrevivência, pois todos os envolvidos estão por livre e espontânea vontade para alcançar os objetivos comuns do grupo. Porém, para analisar as maneiras de participar, necessita-se considerar o contexto histórico e, em muitos casos, as formas de participação são estabelecidas por uma concessão camuflada, as quais não permitem que os cidadãos deixem de ser explorados e manipulados. Ademais, a participação exigida nos empreendimentos coletivos não é inata aos envolvidos, ela somente se tornará realidade se for resultado de um processo educativo e formativo.

$\mathrm{Na}$ análise das diferentes maneiras de participar Bordenave (1985) conclui que há cinco tipos possíveis de participação, sendo eles:

a) Participação de fato: é o primeiro tipo de participação, presente desde os primórdios da humanidade nas atividades básicas de subsistência como as desenvolvidas no núcleo familiar, no culto religioso e na defesa contra os inimigos.

b) Participação espontânea: leva as pessoas a criarem grupos sem organização estável ou propósitos claros e definidos que, na maioria dos casos, é apenas por necessidades psicológicas de pertencer, expressar-se, obter reconhecimento, dentre outras.

c) Participação imposta: ocorre quando a pessoa é obrigada a fazer parte de algum grupo e realiza atividades que são indispensáveis, como por exemplo, as tribos indígenas que obrigam jovens a se submeterem a cerimônias de iniciação e rituais de passagem, ou quando nas nações modernas, obrigam-se os jovens a fazer parte do exército e da disciplina escolar, como também é obrigatório o voto nas eleições.

d) Participação voluntária: são os próprios participantes que criam sua organização e estabelecem seus objetivos e métodos. Esse tipo de participação encontra-se nas associações profissionais, cooperativas, partidos políticos e, podemos incluir também, a participação em um negócio como sócio. Porém, a participação voluntária nem sempre surge como iniciativa dos componentes do grupo, muitas vezes é instigada por agentes externos com objetivos previamente estabelecidos, a fim de alcançá-los, e pode ser chamada de participação provocada, dirigida e/ou manipulada.

e) Participação concedida: esse tipo de participação ocorre "onde a mesma viria a ser a parte de poder ou de influência exercida pelos subordinados e considerada como legítima por eles mesmos e seus superiores." (BORDENAVE, 1985, p. 29). Inclusive, a participação nos lucros, concedida por algumas empresas a seus trabalhadores, também está enquadrada neste tipo de participação.

Ao analisar os tipos de participação de Bordenave, concluímos que esses são instrumentos heurísticos, pois na realidade, nos deparamos com vários desses tipos em uma única organização, dependendo da concepção adotada e da prática exercida. No entanto, a abordagem problematiza a noção de autogestão que expressa a participação plena, sem imposição e subordinação.

Neste sentido, Singer (2002) infere que as práticas de gestão que caracterizam os empreendimentos solidários, denominadas por ele de autogestão, expressam a democracia pela participação dos trabalhadores associados nos rumos da organização e a superação da separação entre o trabalho intelectual, o planejamento, do manual, a execução. Contrapõe essa modalidade de gestão à heterogestão que a caracteriza como uma forma de administração hierárquica, formada por níveis de autoridades, no qual as decisões e ordens são dadas de cima para baixo. Na autogestão, ao 
contrário, todos os sócios se informam do que acontece no empreendimento e das alternativas disponíveis para solucionar os problemas, pois, além de cumprir as tarefas a seu cargo, cada sócio deve se preocupar com os problemas gerais da organização, participar das assembleias e, coletivamente, estabelecer as ordens para os dirigentes.

Ainda que a autogestão seja um conceito polissêmico que expressa experiências diversas, no campo da economia solidária, nomeia a prática de gestão que se caracteriza por relações mais simétricas de poder. Porém, esse modelo democrático e coletivo de gestão é embasado historicamente no ideário socialista, no qual a propriedade, as decisões e o controle do empreendimento são exercidos pelos trabalhadores (NAHAS, 2006). O movimento cooperativista de Robert Owen, os falanstérios de Charles Fourier, a democracia industrial defendida por Proudhon e as Comunas de Paris são exemplos teóricos e práticos de experiências emancipatórias via práticas autogestionárias.

Se a emancipação não foi conquistada com os movimentos cooperativistas, essas práticas não perderam o germe desse processo. Isso tanto é verdade que a autogestão, em seus diversos estágios, revigora as experiências solidárias que lutam pela oportunidade de uma inserção econômica na qual a produção social não seja expropriada dos que a produzem. Assim, Anjos (2014) conclui que os associados dos empreendimentos solidários não têm vivência autogestionária e tampouco compreendem a proposta política da sociedade autogestora. O que a realidade vem demonstrando é que no cotidiano utilizam-se de princípios autogestionários. A gestão é realizada pelos grupos de direção ou conselhos de administração e há mais espaços de participação nos processos decisórios.

A constatação da gestão coletiva nos empreendimentos solidários, segundo Anjos (2014), revela uma ampliação da participação dos que se associam identificados com a economia solidária, todavia, eles não prescindem de formação para assegurar práticas de gestão mais profissionalizadas que resultem na eficiência econômica. Dessa forma, não há como assegurar uma participação qualificada se o empreendimento não conseguir inserir a educação cooperativista, seja ele legalmente uma cooperativa ou não, como um programa que deve ser permanente e processual, tanto para assegurar a dimensão política da ação coletiva quanto à técnica, na gestão empresarial.

\section{Contextualização do Cooperativismo de crédito}

Cooperativas são sociedades de pessoas, com forma e natureza jurídica próprias, constituídas para prestar serviços aos associados, cujo regime jurídico é instituído pela Lei no $5 \cdot 764 / 71$ (BRASIL, 1971). Elas se diferenciam das empresas capitalistas por possuir a finalidade de satisfazer as necessidades sociais e econômicas dos seus sócios, diferente das empresas capitalistas que se preocupam apenas em gerar lucro. O artigo $5^{\circ}$ da Lei 5.764/71 diz que: "As sociedades cooperativas poderão adotar por objeto qualquer gênero de serviço, operação ou atividade, assegurando-se-lhes o direito exclusivo e exigindo-se-lhes a obrigação do uso da expressão "cooperativa" em sua denominação". (BRASIL, 1971). Nessas condições, existem diversos tipos de cooperativas no Brasil de acordo com o ramo de atuação. Dentre eles, destaca-se o ramo crédito que tem apresentado expansão significativa na realidade nacional e no mundo.

Cooperativas de Crédito são instituições financeiras constituídas sob a forma de sociedade cooperativa, tendo por objeto a prestação de serviços financeiros aos associados, como concessão de crédito, captação de depósitos à vista e a prazo, cheques, prestação de serviços de cobrança, custódia, recebimentos e pagamentos, além de outras operações específicas e atribuídas pela legislação em vigor (PINHEIRO, 2008). Segundo o Anuário do Cooperativismo de brasileiro de 2018, as do ramo crédito detinham no Brasil o maior número de cooperados, 9.840.977, associados a 909 cooperativas (OCB, 2019). Dessas, 21 estão localizadas na Bahia, totalizando 120.574 sócios.

Segundo Singer (2002), o cooperativismo de crédito, em termos cronológicos, é o segundo ramo mais antigo, surgiu logo após as cooperativas de consumo. Iniciativa essa, não dos próprios interessados, mas, sim, de figuras políticas que se dispuseram ajudar os pobres por meio de instituições filantrópicas. Antigamente o acesso ao crédito era exclusivo para aqueles que possuíam grandes propriedades, os pequenos produtores não tinham essa oportunidade e quando necessitavam, recorriam a agiotas que cobravam juros abusivos, impossibilitando a liquidação da dívida. 
A adesão a uma cooperativa, de acordo com o primeiro princípio do cooperativismo, é livre e voluntária, os associados admitidos integralizam um valor de quota-parte, fortalecendo o capital social da cooperativa e, ao mesmo tempo, contribuindo para o suporte das atividades financeiras. Os sócios passam a possuir direitos, deveres e obrigações com a mesma, pois além de clientes é direito e dever dos sócios participar das tomadas de decisões e resultados, pois nela os cooperados são donos, proprietários e usuários do empreendimento.

Como instituições financeiras, fazem parte do Sistema Financeiro Nacional (SFN), autorizadas a funcionar e reguladas pelo Banco Central (Bacen) da mesma forma que os bancos comerciais. Segundo Tecchio (2006), uma vez que as pessoas tomam conhecimento que elas estão submetidas ao Bacen, tende a crescer a aceitação e aumentar a participação da sociedade nas cooperativas de crédito.

Pinheiro (2008) afirma que as cooperativas de crédito desempenham um importante papel no desenvolvimento de muitos países. No Brasil não é diferente. Corroborando essa perspectiva, Porfírio, Fernandes e Dantas (2019) defendem que a falta de serviços financeiros em diversos municípios contribuiu para a expansão do cooperativismo de crédito, facilitando, assim, o crédito para as populações mais desassistidas.

No Brasil existem vários sistemas cooperativistas de crédito concebidos por distintas inspirações ideológicas, arranjo institucional e modelos gerenciais. Pinho (2004) classificou essas experiências dividindo-as entre a vertente pioneira e a vertente solidária. Essa última surgiu no início da década de 1990, nas comunidades rurais, entre os setores mais vulneráveis socioeconomicamente. Por sua vez, Búrigo (2010) também afirma que para entender os vários sistemas cooperativistas de crédito do Brasil deve-se considerar as concepções ideológicas e as práticas de gestão. Destaca os quatro maiores, verificando que três atuam embasados em estruturas mais próximas de uma cultura bancária, focando sua operação em ganhos de escala - Sistema de Cooperativas de Crédito do Brasil (Sicoob), Sistema de Crédito Cooperativo (Sicredi), esses atuam com seus próprios bancos cooperativos e o Sistema Unicred Brasil. O quarto é o Sistema das Cooperativas de Crédito Rural com Interação Solidária (Cresol) e as cooperativas ligadas à Associação das Cooperativas de Apoio a Economia Familiar (Ascoob), criados em 1990, ambos ligados a Cresol Confederação.

As cooperativas de crédito conseguem fazer com que o dinheiro chegue às mãos de diversos segmentos que historicamente não foram atendidos pelos bancos privados e públicos, tais como o agricultor familiar, a costureira, o mecânico de automóveis, o pipoqueiro, viabilizando seus projetos e alavancando seus negócios, contribuindo assim com o desenvolvimento econômico da comunidade, do município e da população, promovendo, em certa medida, a justiça social. A participação da população brasileira em Cooperativa de Crédito aumentou, desde 2012, em 27\%, conforme dados do Banco Central do Brasil, em 2016. Elas estão presentes em 44\% das cidades brasileiras, na Bahia, o crescimento é de $16 \%$ ao ano, acompanhando o ritmo nacional (TECCHIO, 2016).

A expansão do cooperativismo de crédito também ocorre por conta da maior compreensão da população sobre o que é o cooperativismo. Esse conhecimento se dá, em certa medida, pelas atividades de educação cooperativista realizadas pelas cooperativas nos municípios dos quais estão atuando, incentivando, assim, a participação dos sócios que levaria à autogestão e a democratização do crédito a parcelas da população que não tinham acesso devido às exigências bancárias.

\section{A experiência da educação cooperativista em uma cooperativa de crédito}

A Cooperativa de Crédito estudada localiza-se no Território do Recôncavo no Estado da Bahia, mais precisamente no município de Governador Mangabeira, com um Ponto de Atendimento Cooperativo (PAC) no município de Cabaceiras do Paraguaçu. O Território do Recôncavo é formado por dezenove municípios do estado da Bahia, abrangendo uma área de $5.221 \mathrm{~km}^{2}$, com densidade demográfica de 107,4 habitantes $/ \mathrm{km}^{2}$ e população de 514.792 habitantes, sendo $66,9 \%$ da população residente em área urbana, de acordo com os dados do Censo Demográfico 2010, do Instituto Brasileiro de Geografia e Estatística (IBGE). 
O município de Governador Mangabeira foi criado em 14 de março de 1962, estende-se por $106,3 \mathrm{~km}^{2}$ e contava com 19.818 habitantes no último censo. A densidade demográfica é de 186,4 habitantes por $\mathrm{km}^{2}$ no território do município. Localiza-se próximo aos municípios de Cachoeira, Muritiba e Cruz das Almas (IBGE, 2010).

Cabaceiras do Paraguaçu foi elevado à categoria de município em 13 de junho de 1989, estende-se por $226 \mathrm{~km}^{2}$ e contava com 17.327 habitantes no último censo. A densidade demográfica é de 76,66 habitantes por $\mathrm{km}^{2}$ no território do município. Localiza-se próximo aos municípios de Aporá, Santo Estêvão e Sapeaçu (IBGE, 2010).

O Município de Itatim foi emancipado em 13 de junho de 1989 , estende-se por $583,4 \mathrm{~km}^{2}$, no ultimo censo contava com 14.522 habitantes. A densidade demográfica é de 24,89 habitantes por $\mathrm{km}^{2}$ no território do município. Localiza-se próximo aos municípios de Santa Terezinha, Tanquinho e Milagres (IBGE, 2010).

A Cooperativa de Crédito foi inaugurada em Itatim, em 2001. Entre 2003 e 2004 foi instalado um PAC em Governador Mangabeira, decisão essa através de Assembleia Geral Ordinária (AGO), realizada no município de Itatim. Em 2006 a sede da cooperativa foi transferida para Governador Mangabeira e, em 2009, foi aberto o PAC de Cabaceiras do Paraguaçu. Hoje a Cooperativa de Crédito atende aos municípios de Governador Mangabeira, Santa Terezinha, Elísio Medrado, Milagres, Iaçu, Castro Alves, Amargosa, Itatim, Cabaceiras do Paraguaçu, Sapeaçu e Cruz das Almas.

A Cooperativa de Crédito estudada é uma singular que está associada a uma Central, localizada no município de Serrinha. A Central é uma cooperativa de segundo grau com forma e natureza jurídica própria, constituída para prestar assistência às suas cooperativas filiadas. A história da Central está interligada com o surgimento da Associação das Cooperativas de Crédito, criada em 1999 com apoio de entidades ligadas aos movimentos sociais do estado da Bahia. Após uma década de caminhada da organização social, foi criada a Central das Cooperativas de Crédito, desde a sua fundação assumiu a missão de organizar, coordenar e fomentar o Cooperativismo de Crédito, promovendo a inclusão social através da provisão de produtos e serviços financeiros e educativos. Desse modo, a seguir é apresentado um organograma hierárquico das organizações para construção desta pesquisa.

\subsection{Perfil dos/as entrevistados/as}

As informações apresentadas a seguir foram coletadas através de dois roteiros de entrevista semiestruturado, um aplicado com 10 (dez) associados e outro com o5(cinco) funcionários, o1(um) diretor-presidente que foi eleito na última assembleia, realizada em 2018, porém o mesmo já tinha uma relação com a cooperativa, pois exercia o cargo de gerência antes de candidatar-se ao cargo de gestor e o1(um) funcionário da Central das Cooperativas de Crédito, que hoje responde como diretor co-gestor. Foram utilizados nomes fictícios para manter o anonimato das pessoas envolvidas na pesquisa.

A faixa etária dos cooperados/as entrevistados/as varia de 21 a 59 anos, a maioria possui pelo menos o1(um) filho. Apenas 02 (dois) cooperados não concluíram o ensino médio, o1 (um) possui curso técnico, o1 (um) possui nível superior completo e 03 (três) estão cursando nível superior, sendo que 02 (dois) deles cursam Gestão de Cooperativas na Universidade Federal do Recôncavo da Bahia UFRB.

Em relação à ocupação profissional dos/as entrevistados/as a maioria exerce atividade agrícola, os/as demais possuem cargos públicos ou outras atividades assalariadas.

Entre os entrevistados/as, 40\% já ocuparam cargos na Cooperativa de Crédito e 6o\% nunca ocuparam ou tentaram ocupar algum cargo, desses, apenas 02 cooperados têm a cooperativa como sua única instituição financeira. Quanto ao tempo de filiação, os entrevistados/as têm entre o3 a 14 anos na cooperativa. Os/as que possuem 14 anos se consideram sócio/a fundador por ter sido um dos primeiros/as a se associar à cooperativa quando instalada no município de Governador Mangabeira, porém os mesmo não são sócios fundadores, pois a cooperativa foi fundada no município de Itatim.

A faixa etária dos funcionários/as e diretores entrevistados/as varia de 22 a 39 anos, a maioria não possui filhos/as. Uma funcionária possui apenas o ensino médio completo, os demais possuem, no mínimo, um curso técnico. Ressalta-se que um funcionário possui graduação em Gestão de 
Cooperativas na UFRB e outro está cursando a mesma graduação na mesma instituição de ensino. O diretor presidente possui pós-graduação em gestão pública e o diretor co-gestor possui pósgraduação em finanças corporativas.

Em relação à função exercida pelos funcionários na Cooperativa de Crédito, há dois caixas; um para cada agência, um agente de crédito, dois escriturários; um desenvolve atividades internas e outro atendimento. Além dos funcionários, há três estagiários. Estes últimos realizam todas as atividades que estejam no nível de alçada da cooperativa, respeitando as limitações e carga horaria contratual. Sobre o tempo de filiação, todos os funcionários/as se associaram a cooperativa por conta do vínculo empregatício, pois para receber salários ou benefícios é necessário ser sócio da cooperativa. O tempo de filiação dos funcionários/as e diretores varia de 2 a 8 anos.

\subsection{Caracterização da cooperativa de crédito}

A cooperativa foi transferida para Governador Mangabeira com o intuito de oferecer um modelo de negócio que contribui com o desenvolvimento social e econômico das comunidades rurais, desassistidas do sistema financeiro tradicional. Atualmente conta com 4.0oo sócios, desses, cerca de 1.500 são ativos. Tem como objetivo social desenvolver programas de poupança, de uso adequado do crédito e de prestação de serviços. Além disso, proporcionar, por meio da mutualidade, assistência financeira aos associados em suas atividades específicas e oferecer a formação educacional de seus associados, no sentido de fomentar o cooperativismo.

Na narrativa dos cooperados entrevistados, a cooperativa é apresentada como uma instituição financeira na qual eles têm facilidade em acessar créditos com taxas de juros mais baixas, com facilidade na contratação e liberação, além do atendimento diferenciado. Observou-se nos relatos que alguns cooperados denominam a cooperativa de banco, isso demonstra a dificuldade em entender e diferenciar as instituições que, apesar de prestar serviços semelhantes, possuem finalidades diferentes. Ademais, verificamos que a maioria se associou apenas para obter os benefícios oferecidos pela instituição financeira, poucos mencionam interesse pelos princípios cooperativistas.

Ao indagar funcionários e diretores sobre as vantagens de ser sócio de uma cooperativa de crédito, uma funcionária responde que a única vantagem se relaciona às taxas de juros baixas e acessíveis, os demais afirmam que os benefícios vão além de taxas menores, como por exemplo, a facilidade na comunicação com a direção, a forma de atendimento, circulação maior de recursos no município, o trabalho social. Em suma, a cooperativa, diferente das outras instituições financeiras tradicionais, oferece aos seus cooperados uma relação de amizade, parceria, gerando benefícios para todos os envolvidos.

\subsection{O processo da educação cooperativista}

Na gestão democrática os sócios devem participar ativamente das tomadas de decisão e na formulação das estratégias que nortearão as ações dos que administram o empreendimento. A Assembleia Geral Ordinária, de acordo com a lei 5764/71, é o órgão supremo das organizações associativas. É nessa reunião que os sócios ficam informados sobre o caminhar da cooperativa, se no exercício anterior houve sobras ou perdas, tomam decisões importantes para o desenvolvimento e conservação, além de votar na eleição de novos membros responsáveis pela gestão.

Na Cooperativa estudada, a AGO acontece uma vez ao ano, conforme a lei, com o prazo máximo de 30 de abril de cada ano. Na última assembleia, realizada no ano de 2018 com a presença de 56 sócios e 13 visitantes, além de apresentar os resultados do exercício de 2017, ocorreu eleição de novos membros para compor a diretoria. Dos sócios entrevistados, 50\% participaram dessa assembleia, porém todos já haviam participado de pelo menos uma AGO. Dentre os que não participaram da assembleia, uma sócia relatou que nem sabia da existência da assembleia geral. $\mathrm{Na}$ época, ela se associou porque a cooperativa possuía uma parceria com a faculdade que estudava. Somente adquiriu conhecimento do que realmente era uma cooperativa quando passou a ser estagiária. Essa experiência demonstra o quanto é indispensável a educação cooperativista, de forma 
continua e permanente, defendido pelos autores Schneider (2003), Vieira e Ricci (2007) citados anteriormente.

A cooperativa, objeto empírico desse estudo, declarou em vários espaços públicos que desenvolviam atividades de educação cooperativista para com os cooperados e seus colaboradores. Desse modo, buscamos compreender a concepção que norteava essas atividades e como elas foram compreendidas. Entre os funcionários, todos já ouviram falar sobre educação cooperativista, esta modalidade educativa é entendida, pela maioria, como uma forma de divulgar o cooperativismo, a cooperativa e seus produtos. É ensinar e mostrar as pessoas à importância da cooperativa na sociedade. Porém, destaca-se um depoimento que considera a educação cooperativista para além dessas contestações:

Pra mim hoje no âmbito do cooperativismo é o fator essencial! Acho que tudo parte do principio da educação, porque hoje a educação é o que dá norte ao empreendimento. Se ela não tiver uma educação de base, aquela educação que transforma do inicio, pra você ensinar ao seu sócio o que é cooperativa, como funciona uma cooperativa, quais são os seus direitos, quais são os seus deveres, a cooperativa não consegue funcionar da maneira adequada. Então, hoje é o que mais falta nas cooperativas e é o fator mais importante. (Rosa, 22 anos).

Os diretores afirmam conhecer o tema educação cooperativista e consideram ser uma forma de capacitação para as pessoas em âmbito geral do desenvolvimento social e econômico, conforme os relatos:

[...] educação cooperativa é você trabalhar o cooperativismo em todos os seus aspectos não só da cooperativa de crédito ou de produção ou de serviço, mas o cooperativismo como alternativa ao capitalismo, como mostrar as pessoas que há outra forma de prover os recursos da comunidade, conseguir falar uma linguagem diferenciada e ao mesmo tempo inclusiva, eu acho que a educação cooperativista vem muito daí. (Raul, 33 anos).

A educação cooperativa é você tá capacitando as pessoas e despertar a consciência do que é o cooperativismo, qual a importância dele para o desenvolvimento local e qual o papel dele enquanto cooperado de uma instituição cooperativa. (Mário, 38 anos).

Schneider (2003) considera que a educação doutrinária é fundamental para nortear as práticas cooperativas, pois é trabalhando os valores e princípios do cooperativismo que cria entre os agentes da cooperação a afinidade e motivação para cooperar e continuar cooperando. Para além dessa reflexão do autor, apenas dois funcionários recordaram todos os princípios. Um funcionário disse que participou de algo que falava sobre, mas já tinha um bom tempo. Dois funcionários afirmaram não conhecer os princípios. Os diretores afirmaram conhecer, porém não souberam citálos.

Quanto à capacitação dos colaboradores, todos, inclusive diretores, afirmaram ter participado de algum momento de formação ofertado pela cooperativa. Porém dificuldades foram citadas para participar dessas atividades, tal como: os funcionários que exercem a função de caixa, pois não têm ninguém que possa substituí-los. Como a maioria das formações é realizada em outro munícipio, os funcionários teriam que se deslocar para participar das atividades, porém quando são realizadas na própria cooperativa, são voltadas exclusivamente para produtos e serviços (taxas de juros, vantagens, forma de contratação, garantias), ocorrem normalmente após o expediente e é ministrada por algum funcionário que possua experiência no assunto ou, se for necessário, a cooperativa pode demandar da Central um funcionário a fim de realizar o treinamento.

Acerca dos temas abordados nas formações, apenas uma funcionária citou o tema educação cooperativista, os demais citaram temas voltados para capacitações nas vendas dos produtos e serviços, inadimplência, renegociação e taxas de juros. A seleção da temática revela uma preocupação com a gestão mais profissional e muito pouco da dimensão social e política da cooperativa. 
Os diretores relataram que estão participando de um curso de Capacitação em Gerenciamento de Cooperativas de Crédito - GERCOOP. Esse curso tem duração de nove meses e os participantes irão se aprofundar nos assuntos do sistema financeiro nacional; fundamentação do cooperativismo; normativas para cooperativas de crédito; governança cooperativa; operacionalização das políticas de crédito de repasse; gestão de risco de crédito; gestão estratégica de pessoas; gestão de singulares e postos de atendimento; elaboração do plano de ação e apresentação.

Sobre a cooperativa conseguir assegurar o quinto princípio do cooperativismo, o diretor presidente dá ênfase aos aspectos mercadológicos, ou seja, a competição que a cooperativa enfrenta com as demais instituições financeiras dificulta a realização de formações que abordem os princípios do cooperativismo. Por outro lado, somente dois colaboradores souberam informar sobre atividades formativas para os sócios, citando as ações de educação financeira. Esses explicam que essas atividades acontecem de acordo à demanda dos sócios e das associações que são clientes.

A partir dos depoimentos dos sócios e colaboradores verificamos que as atividades educativas são raras, basicamente envolvendo aquelas que se destinam á educação financeira, exigência do Bacen, distante se ser permanente e processual. A percepção dessas atividades é distinta entre os colaboradores, para uns, o fato de realizar encontros e atividades, mesmo com baixa participação, já é algo relevante, todavia, outros consideram que atividades educacionais sem impacto social e com pouca participação é improdutivo. Neste sentido, destacamos o pensamento de Vieira e Ricci (2007): "A educação constante do homem para a sua cooperação o torna participativo e comprometido com o sistema, o transforma em defensor intransigente do postulado cooperativo. " (p. o4).

Quanto à percepção dos quatro sócios que já participaram de algum momento de formação promovido pela cooperativa, afirmaram que os temas tratados tanto envolveram questões técnicas, orientações para a produção, quanto discussão sobre cooperativismo e associativismo.

Quando os cooperados foram questionados se já ouviram falar em educação cooperativista e, em caso positivo, qual era a compreensão deles sobre a temática, as respostas demonstraram a distância entre o que era narrado pelos representantes da cooperativa e, de fato, o que acontece na prática. Dois cooperados afirmaram não saber do que se tratava. Outro acredita que a educação cooperativista é o sócio ter direito a desconto ou bolsa de estudo na faculdade. Uma afirma que é parte da comunicação, ensino e formação que os funcionários devem repassar aos cooperados. Um sócio diz que é para mostrar a eles que a cooperativa vai além de obter crédito pessoal e, por fim, um relato que ressalta a carência de atividades que proporcionem a educação cooperativista transcrito a seguir:

Nós temos uma carência muito forte, embora o Brasil viva mais de cem anos de cooperativismo. A educação cooperativista é preparar muito mais que nos espaços das escolas ou das universidades. Preparar a sociedade para um novo momento, para se relacionar com a sociedade, então a educação cooperativa ela deve ser estabelecida no berço, nos primeiros passos da criança, ela deve está discutindo ou vendo ou praticando com a família, da ideia de educação cooperativa ou de cooperativa. Como cooperar é um ato de mutualidade, de trocas, de benefícios por ambas as partes, educação cooperativa ela perpassa por essa formação da pessoa enquanto ainda é jovem, enquanto ainda é criança. (Carlos, 43 anos).

Sobre os direitos e obrigações dos sócios, dois cooperados não conheciam. Os demais consideram que os direitos e obrigações perpassam pela responsabilidade em cumprir com as dívidas contratadas por eles. Para os cooperados entrevistados, ser sócio de uma cooperativa significa ser participativo, presente e ter a facilidade em acessar o crédito nos momentos mais difíceis. Para eles, a cooperativa sempre vai estar à disposição, fortalecendo e atendendo suas necessidades. Conforme relatos:

Significa está em uma instituição que na hora que a gente mais precisa ela está de portas abertas para nos servir, diferente dos bancos que já tem outro olhar, você tem uma conta lá e na hora que você mais precisa ele não olha, as vezes até acha que você não tem condições de pagar aquelas operações de credito. (Ramon, 38 anos). 
É muito mais do que um correntista de qualquer banco, ser sócio de uma cooperativa de crédito é você ser pertencente, é você está enxergando que você tem condições de investir o teu recurso e assegurar esse investimento, que ele vem com retornos, ganhos, rentabilidade muito mais acessível, muito mais presencial do que no banco convencional. Aliás, diga-se de passagem que eu sou testemunha disso, sou correntista em outros bancos, assim como aqui na cooperativa e lá nos bancos convencionais se perde mais do que se ganha na cooperativa de crédito, ser correntista ou ser de poupança, você tem a garantia do seu investimento, o seu dinheiro permanece e só aumenta isso lhe da um conforto e segurança de ser um cooperado nessa instituição. (Carlos, 43anos).

A educação cooperativista, além de fomentar o cooperativismo e os seus princípios, desenvolve o interesse pela participação. Vieira e Ricci (2007) afirmam que:

O estimulo à educação e aprimoramento dos cooperados e de seus dependentes é importante e fundamental em cooperativismo. A própria participação do cooperado, desde que comprometida e solidária, já é uma forma de educação prática do homem no convívio com a sociedade. O desenvolvimento da educação é uma decorrência da preocupação da doutrina com o aperfeiçoamento do homem, permitindo que ele se eduque adquirindo conhecimentos indispensáveis à prática do cooperativismo. (p. 04).

Nessa perspectiva, verificou-se que a participação mais efetiva no cotidiano da cooperativa é relativa. Dos depoentes, três avaliam que participam assiduamente, os demais assumiram que estão distantes dos processos decisórios e que precisam se fazerem presentes. Os motivos para a não participação efetiva são diversos, mas a explicação de um sócio destaca-se:

Na verdade, o povo do nosso Recôncavo não tem a cultura ligada a questão do cooperativismo, ainda é muito tímida comparada as regiões do Sisal, Sertão, mas que a gente tem feito alguns trabalhos ano passado que têm amenizado essa mente do povo. E eu creio que isso futuramente vai tá melhorando muito mais, fortalecendo essa mente, essa cultura que ainda não se tem do cooperativismo. (Ramon, 38 anos).

O reduzido número de cooperativas no Território do Recôncavo e a incipiente cultura com o cooperativismo são obstáculos que precisam ser superados, para tanto faz-se necessário o estímulo a educação cooperativista. Essa educação precisa ser planejada para envolver os cooperados, mas, também a comunidade que não tem clareza sobre quem presta os serviços de créditos acessados, atribuindo esses serviços à atuação da associação que realiza assistência técnica as comunidades rurais.

Bordenave (1985) alertou que para participar é preciso educar. Para ele, a qualidade da participação se eleva por distintos motivos, dentre eles, quando as pessoas aprendem a conhecer a sua realidade, refletir e entender os significados possíveis da palavra participação. $O$ autor ressalta que a origem da palavra participação advém da palavra parte e que as respostas sobre o significado da participação será; fazer parte, tomar parte ou ter parte. Sobretudo, pondera que: "A prova de fogo da participação não é quanto se toma parte mas como se toma parte." (p. 23).

Justamente sobre o significado atribuído à participação pelos cooperados, a maioria considera que participar é tomar parte e fazer parte da organização. Alguns consideram que o fato de estar inserido na cooperativa já é um ato de participação, outros acreditam que participar é estar por dentro do que acontece, ou seja, o cooperado só é participativo se tomar parte, apenas fazer parte não é participar. Dos sócios entrevistados, $60 \%$ deles se consideram participativos. Outros 20\% não se consideram e os demais $20 \%$ se consideram pouco participativos, mas afirmam que pretendem melhorar essa realidade.

As respostas obtidas revelam que os sócios até se consideram participativos, porém, não estão no cotidiano da cooperativa e pouco sabem dos processos decisórios. O número reduzido de associados na assembleia de eleição da diretoria demonstra os desafios que a cooperativa terá de travar para implementar um programa de educação cooperativista que busque qualificar dirigentes e 
colaboradores para uma gestão eficientes, mas, sobretudo, terá que desenvolver ações que motive à participação, condição elementar para uma gestão coletiva que possa ser caracterizada como autogestionária.

A cooperativa precisa desenvolver atividades de formação contínua para seus sócios. Além disso, necessita desmistificar o fato da cooperativa não ser um banco, incluir no seu planejamento as atividades orientadas para essa formação, ainda que estas possam ser realizadas em parceria com a organização social que atua no município prestando assistência técnica. No entanto, urge que haja um esclarecimento a parte dos associados que estão filiados as duas organizações quais as suas similaridades e diferenças.

\section{Considerações finais}

O levantamento bibliográfico, a pesquisa de campo e as observações realizadas durante os estágios possibilitaram analisar a experiência da educação cooperativista em uma Cooperativa de Crédito, em Governador Mangabeira, na Bahia. As atividades que tinham por finalidade promover a educação cooperativista dos sócios ocorreram mais recentemente por exigências do Banco Central, ou seja, ações que envolviam a educação financeira que são realizadas anualmente. As demais formações citadas foram organizadas pela associação que presta assistência técnica e destaca a importância do cooperativismo e associativismo para o desenvolvimento comunitário. A cooperativa realizou algumas atividades educativas, porém estas têm aproximadamente dois anos. Atualmente não existe um trabalho de formação direcionado aos sócios, ainda que a atual direção afirme ser este um dos principais desafios a ser enfrentado porque já diagnosticou o afastamento do quadro social.

Os cooperados entrevistados, mesmo aqueles que participaram de atividades de formação, ainda são desconhecedores do cooperativismo e dos seus princípios. Essa constatação revela a necessidade da educação cooperativista ser contínua e permanente, como defendida por Schneider (2003). Devido à incipiente compreensão da natureza cooperativa por parte do quadro social, detecta-se que não existe uma participação efetiva dos sócios no cotidiano da organização, tampouco parece existir um exercício mais democrático nos processos decisórios.

Percebe-se que a Central da qual participa a cooperativa pesquisada demonstra uma preocupação om a formação dos colaboradores e dos cooperados. Para que as formações sejam realizadas, a cooperativa singular repassa uma contribuição financeira para a Central, que, por sua vez, realiza diversos eventos e formações. No entanto, as atividades que foram oferecidas eram destinadas aos colaboradores com o intuito de qualificá-los para as funções que exerceriam. Nesse contexto, pode-se afirmar que existe um processo de formação para os colaboradores, porém não se constitui em um programa permanente nem continuo.

Finalizada a análise da experiência da educação cooperativista na cooperativa estudada, reafirmamos sua relevância para que não tenhamos uma prática autogestionária idealizada, distante do vivido pelos associados. A educação cooperativista é a base para entender a singularidade da cooperativa que alia dimensão econômica com a solidariedade e a ajuda mútua. É através desse processo que as pessoas poderão compreender e viver o verdadeiro sentido da palavra cooperar. Os princípios do cooperativismo, os direitos e obrigações dos sócios, a participação efetiva, o poder de pertencimento, tudo isso floresce a partir da prática educativa que enfatiza a cooperação nos rumos do empreendimento. A educação cooperativista é sim um caminho para a cooperação, porém como diz Whatkins, citado por Schneider (2003, p.131) "Não pode haver cooperação sem cooperadores, e os cooperadores, diferentemente dos poetas, não nascem, se fazem".

\section{Referências}

ANJOS, E. Os impasses e as potencialidades das práticas autogestionárias das cooperativas de trabalho da economia solidária. Cadernos Gestão Social, v.5, n.2, p.287-305, 2014.

BORDENAVE, J. E. D. O que é participação. São Paulo: Brasiliense, 1985.

BRASIL. Lei 5.764/71. Define a Política Nacional de Cooperativismo. In: Diário Oficial da União, 
Brasília, DF, 1971.

BÚRIGO, F. L. Finanças e solidariedade: Cooperativismo de Crédito Rural Solidário no Brasil. Chapecó: Ed. Argos, 2010.

FERREIRA, P. R.; D. N. SOUSA. O campo da educação Cooperativista e sua relação com o Serviço Nacional de Aprendizagem do Cooperativismo (Sescoop). Interações, Campo Grande, vol. 19, n.4, 2018, p 773-787

FERREIRA, P. R.; SOUSA, D. N.; AMOEDO, N. B. P. Situação da educação cooperativista nas cooperativas agropecuárias de Minas Gerais. Desenvolvimento em Questão, Editora Unijuí, ano 16, n. 42, jan/mar, 2018, p. 518-552.

IBGE. Censo demográfico de 2010. Instituto Brasileiro de Geografia e Estatística, Brasília, 2016.

LAGO, A. Educação cooperativa: a experiência do programa do SICREDI "A união faz a vida". Anais do XLVI Congresso da Sober. Rio Branco, 2008. 18 p.

NAHAS, V. G. Autogestão. In: CATTANI, A. D; HOLZMANN. L (orgs.). Dicionário de trabalho e tecnologia. Porto Alegre: Editora da UFRGS, 2006. p. 36-43.

OCB. Anuário do Cooperativismo Brasileiro. Sescoop: Brasília, 2019.

PINHEIRO, M. A. H. Cooperativas de crédito: história da evolução normativa no Brasil. Brasília: $\mathrm{BCB}, 2008$.

PINHO, Diva Benevides. O cooperativismo no Brasil: da vertente pioneira à vertente solidária. São Paulo: Ed. Saraiva, 2004.

PORFÍRIO, L. V.; FERNANDES, B. V. R.; DANTAS, J. A. Um retrato do cooperativismo de crédito no Brasil: perfil dos municípios brasileiros em dezembro de 2017. RGC, Santa Maria, v.6, n.12, p. 201-218, jul/dez. 2019.

SCHNEIDER, J. O. Pressupostos da educação cooperativa: a visão de sistematizadores da doutrina do cooperativismo. Educação cooperativa e suas práticas, Brasília, 2003. 13-57.

SINGER, P. Introdução à Economia Solidária. São Paulo: Editora Fundação Perseu Abramo, 2002.

TECCHIO, C. Banco pra quê? O negócio é cooperativa de crédito. In: Jornal A Tarde Especial cooperativismo, Salvador, p. 6-7, jul. 2016.

VIEIRA, A.C. M.; RICCI, F. Educação cooperativista percebida como capacitação doutrinária e prática da cooperação para a excelência das ações. In: Encontro Internacional de Economia Solidária "O discurso e a prática da economia solidária”, 5., 2007, São Paulo. Anais... São Paulo: NESOL, ITCPUSP. 2007. p. 1-14.

YIN, R. K. Estudo de caso: planejamento e métodos. Porto Alegre: Bookman, 2010. 